\title{
El asunto sucesorio en las Cortes de Cádiz*
}

\author{
Ángeles Hijano Pérez \\ Universidad Autónoma de Madrid \\ The succesory subject in Cortes of Cadiz
}

\begin{abstract}
RESUMEN ABSTRACT
Esta comunicación defiende dos argumentos: por un lado, estudiar las razones por las que en las Cortes de

Cádiz, recordando la legislación histórica española, se inició una oportunidad de igualdad entre géneros para el acceso a la sucesión al trono que se olvidaría de inmediato y, por otro, indicar que en Cádiz el tema no se trató como una cuestión de género, sino como una búsqueda de la identidad española que les alejaba de Francia, el país invasor, y les acercaba a Gran Bretaña.

PALABRAS CLAVE: género, sucesión, constitución, asunto sucesorio, Ley Sálica.

This communicate defends two arguments: on the one hand, to study the reasons why in Cortes of Cadiz, remembering the historical legislation of Spain, appeared the opportunity of equality between sex kinds for the throne succession, the one would be forgotten immediately, and, in the other hand, to indicate that in Cadiz this subject was not threaten like a sex kind question, but like a search of the Spanish identity that moved away them from France, the invader country, and approached them to Great Britain.

KEYWORDS:

kind, succession, constitution, successor subject, Sálica Law.
\end{abstract}

* Esta comunicación se inserta en un trabajo más amplio, $1+D+1 N{ }^{\circ}$ expediente: 35/05. El origen histórico de la violencia contra las mujeres: Discursos, símbolos, normativa jurídica y realidad cotidiana en España. (1700-2004). 
«Allí no se juega tampoco. Allí no van Quintana el fatuo, ni Martínez de la Rosa el pedante, ni Gallego el clerizonte ateo, ni Gallardo el demonio filosófico, ni Arriaza el relamido, ni Capmany el loco, ni Argüelles el jacobino, sino multitud de personas deferentes con la Religión y con el Rey».

\section{Pérez Galdós, Benito, Episodios Nacionales, Primera Serie, Cádiz, Madrid, Casa editorial Hernando, 1929, p.65.}

\section{INTRODUCCIÓN}

¿Es posible estudiar las razones por las que en las Cortes de Cádiz se inició una oportunidad de igualdad entre géneros para el acceso a la sucesión al trono, recordando la legislación histórica española, que se olvidaría de inmediato? En esta comunicación pretendo contestar a esta pregunta ya que es obvio que se produce una contradicción, pues la posibilidad de que las mujeres pudieran heredar el trono contrasta con el olvido que tuvo su presencia en las discusiones de las mismas. La mayoría de los trabajos realizados sobre su importancia en las Cortes coincide en que fueron olvidadas. Aquí haremos un repaso a esas situaciones donde quedaron invisibles, pero nos acercaremos a esa otra cuestión que no se ha analizado hasta el momento, la posibilidad de que las mujeres pudieran heredar el trono. Ese problema obligaba a ser respetuosos con las tradiciones españolas para alejarse del modelo francés, aunque no tuvo consistencia suficiente para ser materia discutida en Cortes.

La controversia monarquía o república no se planteó en el primer constitucionalismo español. Es más, en esas fechas la población era mayoritariamente defensora de la monarquía, como bien pusieron de manifiesto los defensores del trono de Fernando VII. Ni siquiera los diputados liberales, contrarios a este rey, pudieron luchar contra su absolutismo más que a base de escritos donde se sugerían proyectos de Constitución y se solicitaba la restricción de los poderes del monarca ${ }^{1}$.

Es también la oportunidad para manifestar el escaso aliciente que en 1808 existía en España a favor de la igualdad, pues no había un movimiento que reivindicara nada en este sentido. El retraso con respecto al movimiento feminista británico, hacía muy difícil convertir esa posibilidad en algo necesario para la población$^{2}$. Es muy curioso comprobar, mediante una mínima observación, la falta de

1 Varela Suanzes-Carpegna, Joaquín, «Álvaro Flórez Estrada un liberal de izquierda», en Moreno Luzón, Javier (Ed.), Progresistas, Madrid, Taurus, 2005, p. 26.

2 En estas fechas España está dentro de los moldes del patriarcado burgués, por lo que las razones de inferioridad y desigualdad jurídica de la mujer le afectan plenamente. Cfr. Gerhard, Ute, «La situación jurídica de la mujer en la sociedad burguesa del siglo XIX. Un análisis comparativo de Francia y Alemania", en Fradera, Josep M. ${ }^{a}$ y Millán, Jesús (Eds.), Las burguesías europeas del siglo xx. Sociedad civil, política y cultura, Valencia, Biblioteca Nueva, 2000, p. 333. 
interés por problemas relacionados con las mujeres, pues parece que éstas no formaban parte de la sociedad española ${ }^{3}$. Este resultado de olvido de las mujeres en la Constitución de Cádiz se puede obtener con la consulta del Diario de Sesiones de las Cortes, fondo donde se aprecian las carencias sobre este asunto, así como lo innecesario que resultaba para los diputados debatir sobre esas materias ${ }^{4}$. En cualquier caso, en estas líneas no se pretende hacer un estudio de historia de género, en una materia sobre la que hay muchas especialistas, autoras de obras importantes ${ }^{5}$, sino que es una aportación mucho más modesta que sólo trata de situar a la mujer en un puesto que teóricamente se le había permitido utilizar legalmente, aunque eso no diera pie a ninguna clase de debate ni a una proyección posterior. Está bastante claro que al colectivo de mujeres el liberalismo no les aportó ningún reconocimiento.

La parte final de la comunicación será un esbozo sobre la Ley Sálica, texto mediante el cual se marcaron las diferencias de género en el pasado y que continúa dando sus coletazos en el presente. En este tema es donde la comunicación intenta poner de manifiesto que el asunto sucesorio en Cádiz se trató de la forma más lógica para la época, es decir, retomando la tradición de la legalidad española, olvidándose de esa normativa impuesta por Felipe V, que les acercaba a Francia y les alejaba de Gran Bretaña. No se trataba tanto de una cuestión de género, como de una búsqueda de la identidad española que buscaba reflejar en la normativa del nuevo estado las esencias propias de la legislación estatal más antigua y de mayor aceptación en la historia de España.

\section{EL ENTORNO SOCIAL}

Para analizar cómo era el entorno social gaditano se puede seguir la obra de uno de los más importantes escritores costumbristas de la literatura española, Benito Pérez Galdós, pues en uno de sus escritos, nos encontraríamos ante la situación vivida por los habitantes de Cádiz, justo cuando se iniciaba el proceso de apertura de las Cortes ${ }^{6}$. La población gaditana se mostraba fascinada y deseosa

\footnotetext{
3 NiELFA, Gloria, «La revolución liberal desde la perspectiva del género», en GómEZ-FERRER MoRANT, Guadalupe, ed. Las relaciones de género, Ayer, núm. 17, Madrid, 1995, pp. 114-115. Sobre este punto, recoge los acertados comentarios tanto de Bartolomé Clavero, como de Manuel Pérez Ledesma, ambos resaltando la negativa a que la mujer disfrutara de derechos políticos.

4 Los estudios realizados para estas fechas han tratado de las desigualdades en los terrenos privados y sociales, pero no en el ámbito político. Cfr., Capel Martínez, Rosa M. ${ }^{a}$ [coord.], Mujeres para la historia. Figuras destacadas del primer feminismo, Madrid, Abada editores, 2004, p.8.

5 Para estos estudios hay, afortunadamente, muchas especialistas que serán citadas a lo largo de la comunicación, tales como Gloria Nielfa, Pilar Pérez Cantó, Rosa Capel o Gloria Espigado, autoras de estudios sobre las mujeres en las Cortes de Cádiz.

${ }^{6}$ Las alusiones al costumbrismo galdosiano son casi una práctica habitual cuando se estudian etapas históricas relacionadas con las Cortes de Cádiz. Cfr., SÁNCHEZ VILLANUEVA, Juan Luis, «Una tertuliana, una fourerista: Margarita López de Morla», en Pascua Sánchez, M. a José de la, Espigado Tocino, Gloria (eds.), Frasquita Larrea y Aherán europeas españolas entre la llustración y el Romanticismo
} 
de conocer la innovación de ese invento de las Cortes. Estaba confusa y curiosa, preguntándose qué les proporcionaría eso de lo que hablaban todos, ... «las Cortes, las Cortes", seguro que era algo especial, pues así se apreciaba en la gran movilización realizada para ordenar el escenario, en la llegada de numerosos personajes de la política y de grandes clérigos, poseedores de un verbo de oro. Aunque la novela de Galdós nos retrate el ambiente del momento, es evidente que su relato puede ser poco creíble, incluso engañoso, y está claro que la información más certera sobre ese acontecimiento es la proporcionada por los documentos del diario de sesiones del Congreso de los diputados. La aportación de la novela, como muy bien indica Isabel Burdiel, no sería más que un recuento anecdótico que apenas ampliaría nuestros conocimientos, por lo que si quisiéramos convertir sus informaciones en datos relevantes, haríamos algo realmente ridículo ${ }^{7}$. Algunas autoras cuestionan la veracidad de la obra de Galdós, aunque intenten hacer comparaciones entre personajes de la novela e individuos conocidos de la sociedad gaditana ${ }^{8}$. No obstante, aunque partamos de esa realidad, no podemos olvidar que el costumbrismo de nuestro autor consigue emocionarnos y hace que casi lleguemos a visualizar cuál era el ambiente de aquellos momentos.

Los protagonistas describen a los políticos que se encuentra en Cádiz con gran soltura, aludiendo a su aspecto, a su juventud, al permiso obtenido para acceder a la tribuna, aunque no tuvieran la edad. Es curioso que esa información, conseguida en los libros sesudos de la época, aparezca en una novela en la que sólo se describe la opinión de algunos personajes del momento acerca de la celebración de las Cortes. Se alude al vizconde de Matarrosa, para referirse al que más tarde sería conde de Toreno, haciendo comentarios sobre su juventud y sobre que debería estar mamando, pese a ello era tan capaz que sabía inglés:

«-Desde aquí veo al vizconde de Matarrosa —indicó doña Flora-. Es aquel mozalbete rubio. Le he visto en casa de Morla, y es chico despejado... Como que sabe inglés. -Ese angelito debería estar mamando, y le van a dispensar la edad para que sea diputado -observó la Condesa-. Como que no tiene más años que tú Gabriel. Vaya unos legisladores que nos hemos echado. Aquí tenemos Solones de veinte abriles» ${ }^{9}$.

Se habla de algunos de los políticos más importantes del momento, a los que el autor describe con tremenda habilidad para ridiculizarles:

(1750-1850), Junta de Andalucía, Instituto andaluz de la Mujer, Universidad de Cádiz, Servicio de Publicaciones, 2003, pp. 157-180.

7 BuRdiEL, Isabel/ SERNA, Justo, «Literatura e historia cultural o Por qué los historiadores deberíamos leer novelas", en Eutopías 2. é época. Documentos de trabajo, Valencia, Episteme, Vol. 130, 1996, pp. 3-4.

${ }^{8}$ Gloria Espigado critica, sobre todo, la mofa que hace Pérez Galdós de la actitud femenina. Cfr. EsPIGADO TOCINO, Gloria, «Mujeres y ciudadanía, del antiguo régimen a la revolución liberal», en Mujeres y ciudadanía en el primer liberalismo español, Barcelona, Debats, 2003.[http://seneca.uab.es/hmic].

9 Pérez Galdós, Benito, Episodios Nacionales, Primera Serie, Cádiz, (Desde ahora, Cádiz ) Madrid, Casa editorial Hernando, 1929, p. 84. 
«QQué bonitos habrían estado Argüelles, Muñoz Torrero, García Herreros, Ruiz Padrón, Inguanzo, Mejía, Gallego, Quintana, Toreno y demás insignes varones, vestidos de arlequines! ${ }^{10}$.

Sorprende leer una novela donde las estrellas son los sujetos que toman la palabra en las Cortes de Cádiz para configurar un nuevo modelo de Estado. En Cádiz se muestra una versión de la combinación entre literatura e historia, dando muestra de las grandes conexiones que se pueden encontrar y del enriquecimiento que proporcionan a cada una de las disciplinas. Se hacen muchas alusiones a Muñoz Torrero, el diputado del que hablaremos para destacar su discurso de negación de derechos a las mujeres, pero aquí se habla de él como de un diputado que diserta muy bien, sin ninguna otra consideración:

«En los palcos inmediatos corría de boca en boca un nombre que llegó hasta el nuestro. El orador era D. Diego Muñoz Torrero. Señores oyentes o lectores, estas orejas mías oyeron el primer discurso que se pronunció en asambleas españolas en el siglo XIX. Aún retumba en mi entendimiento aquel preludio, aquella voz inicial de nuestras glorias parlamentarias, emitida por un clérigo sencillo y apacible, de ánimo sereno, talento claro, continente humilde y simpático. Si al principio los murmullos de arriba y abajo no permitían oír claramente su voz, poco a poco fueron acallándose los ruidos y siguió claro y solemne el discurso. Las palabras se destacaban sobre un silencio religioso, fijándose de tal modo en la mente que parecían esculpirse. La atención era profunda, y jamás voz alguna fue oída con más respeto ${ }^{11}$.

Pese al interés por el espectáculo, la población se sentía muy al margen de las Cortes. Para el ciudadano de a pie el representante más importante de la política era su rey y no todo el grupo de políticos, intelectuales admirados por sus conocimientos pero que no trasmitían confianza al pueblo. Aunque las clases populares eran analfabetas en su mayoría y no se planteaban los problemas sobre los que debatían los políticos, en Cádiz había actividades tertulianas seguidas por varias mujeres gaditanas y sevillanas de la época, que participaron en la creación de asociaciones de mujeres que, cuando menos, contribuyeron a su socialización en estos primeros años del liberalismo ${ }^{12}$.

Sin embargo, y eso es probablemente lo más importante, ni la novela de Pérez Galdós ni los diarios de sesiones de las Cortes proporcionan el caudal de información que sería necesario para explicar el argumento planteado en mi comunicación. En ninguno de los casos se menciona la cuestión objeto de mi estudio. Nadie menciona en la novela la posibilidad de que una mujer pudiera ser la heredera

10 Pérez Galdós, Benito, Ibidem, p. 54.

11 Pérez Galdós, Benito, Op. Cit., p.86-87.

${ }^{12}$ Espigado Tocino, Gloria. «La Junta de Damas de Cádiz: entre la ruptura y la reproducción social», en Pascua Sánchez, M. ${ }^{a}$ José de la, Espigado Tocino, Gloria (eds.), Frasquita Larrea y Aherán europeas españolas entre la llustración y el Romanticismo (1750-1850), Junta de Andalucía, Instituto andaluz de la Mujer, Universidad de Cádiz, Servicio de Publicaciones, 2003, pp.243-266. 
del trono, según quedaría establecido en el texto de $1812^{13}$. En el debate de las Cortes tampoco se le da gran importancia a ese asunto, pues en Cádiz lo que se hizo, con respecto al asunto sucesorio, fue retomar la tradición de la legalidad histórica española, dejando muy claro el rechazo a las normas francesas que imponían una realidad ajena a los modos españoles. La población debía considerar que los asuntos de herencia del trono quedaban fuera de sus intereses y, desde luego, no se plantearon esa cuestión.

\section{EL OLVIDO DE LAS MUJERES EN LAS CORTES DE CÁDIZ}

El paso de los años ha puesto de manifiesto que Cádiz supuso una oportunidad perdida en ese intento de buscar la igualdad. La historia de la que se habla en Cádiz es una historia androcéntrica, en la que el masculino no es considerado como universal genérico, sino como el sujeto de la acción. Ni las mujeres gaditanas ni ningún miembro de la sociedad tenían en mente esos problemas. Para ellos las Cortes eran un cúmulo de sorpresas de las que no se sabía qué podrían traer. Las Cortes se interesaron en debatir sobre los problemas de la igualdad, obteniendo conclusiones importantes, tales como distinguir entre derechos civiles y políticos, pero negándole a la mujer el disfrute de los mismos. De este modo, las mujeres no fueron objeto inicial de debate y, tanto es así, que se les negó la posibilidad de tener derechos políticos casi por casualidad. El diputado Muñoz Torrero en un importante discurso del 6 de septiembre de 1811, aludió a las mujeres, negándoles esos derechos políticos, pero sólo para ponerlas como ejemplo y, gracias a ello, poder negarles a las castas la concesión de la categoría de ciudadanos. No obstante, de Muñoz Torrero se habla bastante en Cádiz, pues buena parte de los comentarios sobre las Cortes se centran en algún discurso suyo. La novela de Galdós hace una lectura certera de lo que se estaba produciendo, llegando a afirmar, en relación a un discurso del diputado Muñoz Torrero:

"Cuando la última palabra expiró en sus labios, y se sentó recibiendo las felicitaciones y los aplausos de las tribunas, el siglo decimoctavo había concluido. El reloj de la Historia señaló con campanada, no por todos oída, su última hora, y realizóse en España uno de los principales dobleces del tiempo» ${ }^{14}$.

No puede extrañarnos la ausencia de una consideración problemática sobre la igualdad de las mujeres en pleno inicio del siglo XIX. En esas fechas no sólo en Es-

${ }_{13}$ En Cádiz, hay muchas alusiones a las discusiones de las Cortes, pero nunca se habla de esa materia. Se comenta en muchas ocasiones de Paquita Larrea, la esposa del Sr. Böhl de Faber, y se hacen descripciones como la siguiente: «Debo indicar, que doña Francisca Larrea, esposa del entendido y digno alemán Böhl de Faber, era mujer de mucho entendimiento, escritora, lo mismo que su marido a quien eran muy familiares los primores de la lengua castellana. De este matrimonio, nació Eliseo Böhl, a quien debemos las mejores y más bellas pinturas de las costumbres de Andalucía, novelista sin igual y de fama tan grande como merecida dentro y fuera de España» PÉREZ GaLdós, Benito, Op. Cit., p.169.

14 Pérez Galdós, Benito, Op. Cit., p. 87. 
paña, sino en buena parte de Europa y del mundo la mujer no era considerada desde la perspectiva del género ${ }^{15}$, sino como un elemento que sólo representaba un papel para la reproducción o como un adorno en cualquier acontecimiento. Estaba alejada de la política y esa era una consigna reiterada por muchos políticos de la época ${ }^{16}$. Nadie pudo hacer una lectura diferente en estas fechas. A nadie se le ocurría que la existencia de una reina tuviera algún objetivo de búsqueda de igualdad. No podía ser de otro modo, la monarquía se movía según los parámetros tradicionales y la aparición de una supuesta mujer como heredera se debía a razones políticas y, desde luego, nada relacionadas con las cuestiones de género. Es más, en Cádiz, como muy bien han indicado muchas autoras no se habló de mujeres, casi para nada y, desde luego, las mujeres no estaban en el horizonte de los problemas a discutir. En un artículo sobre las Cortes de Cádiz, Pilar Pérez Cantó indica que la Constitución de 1812 fue «una reflexión sobre lo que pudo ser y no fue... ${ }^{17}$. La autora lamenta las buenas expectativas que aparentemente había conseguido la mujer para llegar a Cádiz, pero que finalmente le siguieron manteniendo en el modelo de exclusión. No obstante, la misma autora explica que en Cádiz había tertulias con mujeres cultas y preparadas, capaces de debatir sobre el modelo social que se les estaba preparando ${ }^{18}$.

También se ha quejado Gloria Espigado de la ocultación que supusieron las Cortes de Cádiz para las mujeres:

«Pero en las Cortes de Cádiz, lo que nos encontramos son varias posibilidades para la neutralización a toda posible aspiración de protagonismo femenino en el nuevo marco político que se está fraguando. El discurso de los hombres, que parcialmente será discurso liberal, cuando no será servil, pero coincidente en el tratamiento que hay que ofrecer a las mujeres, es, no obstante, variado en su escala de presentación, pero acorde en el objetivo de preservar la exclusividad de lo político a los varones... $\gg^{19}$.

${ }^{15}$ El concepto género se entiende aquí, siguiendo los parámetros defendidos por Gisela Bock, es decir, la defensa de ese concepto, como una categoría fundamental de la realidad social, cultural e histórica... «Una de las razones esenciales de la introducción del término "género" en este amplio sentido y de su rápida difusión como sustituto de la palabra «sexo»». Vid., BOCK, Gisela, "La historia de las mujeres y la historia del género: aspectos de un debate internacional», en Historia Social, n. ${ }^{\circ}$, invierno 1991 , p. 59.

16 "La cuestión del género en la política», en Bárbara Caine y Glenda Sluga, Género e Historia. mujeres en el cambio sociocultural europeo de 1780 a 1920, Madrid, Narcea, 2000, p. 81. En este libro se indica que «[l]a codificación de los derechos y la representación siempre supuso una sistemática negación de los mismos a la mujer».

17 Pérez Cantó, Pilar, «Las Cortes de Cádiz y la construcción de la ciudadanía», en Pilar Pérez Cantó y Susana Bandieri —compiladoras-, Educación, género y ciudadanía, capítulo 5, Miño y Dávila, Madrid, 2005, p. 161.

${ }_{18}$ Las mujeres construyeron espacios de sociabilidad femenina, mediante tertulias y organización de sociedades, como la Sociedad de Señoras de Fernando VII, que funcionó de 1811 a 1815 . Vid. PéreZ CANTó, Pilar, Op. Cit.., pp. 175-177.

${ }^{19}$ EsPIGADO TociNo, Gloria, «Mujeres y ciudadanía, del antiguo régimen a la revolución liberal», en Mujeres y ciudadanía en el primer liberalismo español, Barcelona, Debats, 2003, [http://seneca.uab.es/hmic]. 
Resulta desolador que ese fantástico escenario que habrían sido las Cortes de Cádiz se quedara en un fraude completo. No obstante, era algo previsible, pues desde el 26 de septiembre de 1810 se declaró que debía negarse a las mujeres la entrada a la Asamblea. Gloria Nielfa resalta la prohibición expresa de los Reglamentos de 1810, 1813 y 1821 para que las mujeres no pudieran asistir a los debates del Congreso ${ }^{20}$. Parece que hubo una petición por parte de un grupo de mujeres contra esa prohibición, aunque no se eliminó, así como un episodio en el que algunas mujeres se disfrazaron de hombres para asistir a las sesiones de Cortes $^{21}$.

Bartolomé Clavero, por su parte, considera que las mujeres no fueron consideradas en Cádiz como sujeto de derechos. La mención a la obra de Clavero se ha convertido en un referente casi obligado para todos los historiadores que indagamos sobre la posición de la Cortes de Cádiz ante las mujeres, pues, además es uno de los pocos autores que ha resaltado la exclusión de las mujeres en Cádiz, al no permitirles concurrir a los espacios de ciudadanía que se estaban poyectando y dejarlas en situaciones tan precarias como las de los esclavos ${ }^{22}$. Es más, el estereotipo femenino que ya se estaba desarrollando, existía para indicar que había lugares a los que la mujer no debía aspirar y, por supuesto, la utilización del poder era algo imposible para una mujer ${ }^{23}$.

En un monográfico sobre las Cortes de Cádiz ${ }^{24}$, sólo el artículo de Manuel Pérez Ledesma menciona a las mujeres en el apartado donde se habla de «español y ciudadano: igualdad civil e igualdad política». Aquí se intenta explicar las argumentaciones utilizadas en Cádiz para negarles la igualdad a las castas, pretensión de los diputados americanos. La escasa presencia de las mujeres en la obra de prestigiosos autores no se debe a ninguna intención perversa de seguir marginando a la mujer, sino que se produce por el reflejo más certero de la realidad de la situación, es decir, apenas se puede mencionar a las mujeres porque no fueron casi objeto de discusión y no lo eran, sencillamente porque estaban desprovistas de ese derecho a la participación. Para explicar cómo se produjo el rechazo a la mujer debe hacerlo partiendo del discurso realizado por el diputado Muñoz Torrero cuando explicaba a la Cámara las diferencias existentes entre derechos civiles y políticos. $\mathrm{Ni}$ el origen ni la formación ni las exigencias educativas, eran argumentos suficientes para negarles los derechos políticos a las castas, y se le ocurrió

20 NiELFA, Gloria , «La revolución liberal desde la perspectiva del género», en GómEZ-FERRER MoRANT, Guadalupe, ed. Las relaciones de género, Ayer, núm. 17, Madrid, 1995, pp 117-118.

21 Pilar Pérez Cantó, citando a Alcalá Galiano, también recoge esa prohibición a las mujeres de asistir a las Sesiones de Cortes, como se establecía en el Cap. I, Art. 3. ${ }^{\circ}$ de su Reglamento de 1810. Vid. Pérez Cantó, Pilar, Op. Cit., p. 175.

22 Clavero, Bartolomé, «Cara oculta de la Constitución: Sexo y Trabajo», en Revista de las Cortes Generales, n. ${ }^{\circ}$ 10, Primer cuatrimestre, 1987, pp. 11-25.

${ }^{23}$ Cfr. Nielfa, Gloria, «La revolución liberal desde la perspectiva del género», en GómEZ-FERRER MoRANT, Guadalupe, ed. Las relaciones de GÉNERO, Ayer, núm. 17, Madrid, 1995, pp. 104-105. La autora explica la forma en que se construyeron en estas fechas los roles masculino y femenino.

24 Artola, M. ed., Las Cortes de Cádiz, Ayer, núm. 1, Madrid, 1991. 
el recurso de la reducción al absurdo en su discurso ${ }^{25}$. Sólo así podría convencer a los demás diputados de lo imposible de su petición, pues era tan disparatado como dejar que las mujeres participaran. Recogeremos aquí un extracto de ese discurso, tantas veces mencionado, que era muy brillante en sus inicios, pero con un final sobradamente conocido en lo que respecta al rechazo a la mujer:

«... Hay dos clases de derechos, unos civiles y otros políticos: los primeros, general y comunes a todos los individuos que componen la Nación, son el objeto de la justicia privada, y de la protección de las leyes civiles; y los segundos pertenecen exclusivamente al ejercicio de los poderes públicos que constituyen la soberanía. La comisión llama españoles á los que gozan de los derechos civiles, y ciudadanos á los que al mismo tiempo disfrutan de los políticos.

Con esa explicación parecía tener todo ganado, pero no servía ante los diputados americanos, a los que tuvo que darles más ejemplos...

...Pondré un ejemplo. Los señores americanos que están en el Congreso han gozado hasta ahora de todos los derechos Civiles ¿Pero han disfrutado por ventura de los derechos políticos? ¿Han tenido parte alguna en el ejercicio de la soberanía nacional? ¿No es esta la primera vez que concurren á ejercer en las Córtes la potestad legislativa? Los españoles mismos de la Península nos hallamos en el mismo caso, pues no hemos gozado de los derechos políticos en los términos que se ha verificado para la celebración de las Córtes actuales. Esta es también la primera vez que hemos sido llamados al nombramiento de Diputados de Córtes. La justicia, es verdad, exige que todos los individuos de una misma Nación gocen de los derechos Civiles; mas el bien general, y las diferentes formas de Gobierno, deben determinar el ejercicio de los derechos políticos, que no puede ser el mismo en una Monarquía que en una democracia o aristocracia...

Fue el momento de reducir al absurdo las argumentaciones de los diputados americanos y el mejor modo que se le pudo ocurrir era el ejemplo de las mujeres. ¿Cómo iban a dársele esos derechos a las mujeres?...

...Algunos señores americanos, desentendiéndose de esta distinción, han hablado largamente de las reglas de la justicia, en que debe fundarse toda buena política, y lo mismo hizo ayer el Sr. Torrero. Pero si llevamos demasiado lejos estos principios de lo que se dice rigurosa justicia sin otras consideraciones, seria forzoso conceder á las mujeres con los derechos civiles los políticos, y admitirlas en las juntas electorales y en las Cortes mismas» ${ }^{26}$.

Se cerraba un espectáculo negativo para con los derechos de la mujer.

25 Pérez Ledesma, Manuel, «Las Cortes de Cádiz y la sociedad española», en ArtolA, M ed., Las Cortes de Cádiz, Ayer, núm. 1, Madrid, 1991, pp. 167-206, especialmente, p. 188.

${ }_{26}$ Cfr. Diario de Sesiones de las Cortes Generales y Extraordinarias, sesión de 6 de septiembre de 1811, pág. 1790. (Desde ahora, Diarios.) 


\section{EL DEBATE SOBRE LA SUCESIÓN}

Si abrimos un ejemplar de la constitución de Cádiz de 1812, en su Título IV, Capítulo II, art. 174, leeremos lo siguiente:

\section{CAPÍTULO II, De la sucesión á la Corona}

Art. 174. El Reino de las Españas es indivisible, y solo se sucederá en el Trono perpetuamente, desde la promulgación de la Constitución, por el órden regular de primogenitura y representación entre los descendiente legítimos varones y hembras de las líneas que se expresarán ${ }^{27}$.

Desde la perspectiva actual no parece posible admitir que en 1812 la constitución declarara que el trono de España podría ser ocupado por hombres o mujeres. Después de constatar la escasa importancia dada a la mujer en las discusiones de Cádiz se puede interpretar que las mujeres no podían ser titulares del trono de España, pues ya hemos comprobado que a comienzos del siglo XIX las mujeres y los hombres españoles partían de la admisión de una serie de principios inalterables. La tradición, el privilegio y otros valores similares eran los imperantes entre la población, y, por esos motivos, no era fácil entender el contenido de ese artículo.

Algo fallaba y no estaba presente en el debate sobre la sucesión, sino que formaba parte de una doctrina muy anterior a la constitución de Cádiz que los diputados gaditanos no quisieron discutir por miedo a que sus debates fueran conocidos internacionalmente y les provocara problemas con las potencias europeas.

En la búsqueda de las razones por las que se admite la posibilidad del trono para las mujeres hay que retrotraerse en el tiempo para buscar la primera ley sucesoria de la monarquía castellana. Esa ley, según indicaba en 1839 el jurista alemán Zöpfl, se remonta a fechas anteriores al siglo X cuando se acreditó que en España la corona había sido siempre trasmitida tanto a las hembras como a los varones. En la evolución de la monarquía se constató la herencia en los individuos de una familia determinada, así como el reconocimiento de sentimientos de afección natural, regulados por la proximidad de grado y línea. Este era el orden de sucesión que la jurisprudencia civil y el derecho público habían distinguido bajo la denominación de cognaticio y que había sido muy útil para la monarquía española, por impedir que la falta de hombres en algunas familias alterara o paralizara el orden sucesorio ${ }^{28}$.

La sorpresa hace pensar en una confusión, pues no es probable que a comienzos del siglo XIX, por muy innovadora y revolucionaria que fuera la constitución se hubiera alterado un criterio arraigado en España, desde que Felipe $V$ dictara en

27 Diarios, sesión de 17 de marzo de 1812, número 523, pág. 2937.

28 Volveremos a esta materia, pero conviene citar ya uno de los mejores libros sobre esta cuestión. Vid., ZöPfL, Enrique, Bosquejo histórico sobre la sucesión a la Corona de España, París, Imprenta de Chapelet, Librería de Amyot, 1839, pp. 6-9. 
1713 un Auto Acordado que establecía las normas sucesorias de forma absolutista y arbitraria. Esa alteración de la normativa sucesoria tradicional fue justificada por el rey alegando a las obligaciones impuestas por las conversaciones de Utrecht, pero lo más importante es que con ella se rompía el carácter cognaticio de la sucesión española, razón por la que las Cortes de Cádiz recuperaron ese carácter cognaticio y Argüelles no quiso dar pie a mayores discusiones sobre el particular.

El Auto Acordado de Felipe V decía lo siguiente: «Mi consejo de estado me ha expuesto las razones de conveniencia pública de formar un nuevo reglamento para la sucesión de esta monarquía, a fin de conservar en ella la agnación rigurosa, prefiriendo siempre los varones a las hembras, aunque estas sean de mejor grado y línea. Para mayor seguridad de mi resolución, aunque sin estar obligado a ello, pues como primero y principal interesado en la regla de sucesión para lo interior de mi familia, soy dueño de disponer su establecimiento, quise oír el dictamen del consejo de Castilla, siendo este de dictamen que concurriese el reino al establecimiento de la nueva ley.... mando que de aquí en adelante se regule la sucesión de estos reinos en la forma siguiente: establece la agnación de forma rigurosa y en defecto de varón llama á la hembra mas inmediata al último poseedor, como cabeza de línea, siempre agnaticia; y después de la extinción de toda la descendencia llama á la casa de Saboya, bajo el mismo orden agnaticio: revocando la ley de Partida y la costumbre antigua" 29 .

Con este comienzo se alteraba por completo la costumbre española y se cometía un acto de despotismo arbitrario, razón lógica para que los constituyentes gaditanos quisieran volver a su tradición.

Veamos cómo se inició la obra de las Cortes de Cádiz hasta llegar al tema de la cuestión sucesoria. Siguiendo de forma puntual el discurso preliminar de las bases que debían respetarse en la redacción del texto, los constituyentes iniciaron de inmediato su trabajo, como demuestra la sesión del día 9 de diciembre de 1810 en la que el Sr. Oliveros hizo una proposición donde se pedía formar una comisión de ocho personas para que realizara un proyecto de constitución política de la Monarquía ${ }^{30}$. La propuesta fue admitida a discusión, quedando aprobada por el Congreso. El mismo día el Sr. Muñoz Torrero propuso que esa comisión presentara en un plazo de ocho días un proyecto de decreto para ofrecer un premio al autor de la mejor Memoria sobre la Constitución política de la monarquía ${ }^{31}$, pero quedó pen-

29 ZöPfl, Ibidem, pp. 88-89.

30 Cfr. Primera del Sr. Oliveros: «Que se nombre una comisión de ocho individuos, cuando menos, para que teniendo presentes los trabajos preparados por la Junta Central, proponga un proyecto de Constitución política de la Monarquía.» Cfr. Diarios, sesión de 9 de diciembre de 1810, p. 153.

31 Cfr. Segunda, del Sr. Muñoz Torrero: «Que esta misma comision presente dentro de ocho días un proyecto de decreto ofreciendo un premio al autor de la mejor Memoria sobre la Constitucion política de la Monarquía, señalando para la admision de esta Memoria el 19 de Marzo próximo, sin perjuicio de que la misma comision se ocupe en adelantar y reunir los trabajos expresados.» Diarios..., Tomo IV, sesión de 9 de diciembre de 1810, pág. 153. 
diente de discusión hasta el día 12 del mismo mes, aunque se aprobó la primera parte de su petición en la que se incitaba a llamar para formar parte de la comisión a los individuos más competentes. Con esos prolegómenos, el día 23 de diciembre de 1810, el presidente de las Cortes, Sr. Espiga, declaró quiénes eran los miembros de la comisión de Constitución ${ }^{32}$. Esos diputados no comenzaron sus tareas hasta el día 25 de agosto de 1811, pero lo más llamativo de esa comisión es que estaba formada por individuos de todos los territorios que, según el Título I de la Constitución, podían ser considerados como integrantes de la Nación española, es decir, españoles de ambos hemisferios, lo cual no parece que se tuviera en cuenta para evitar las complicaciones y desigualdades que se manifestarían a lo largo de los debates. Puede afirmarse que esa comisión no era paritaria, sencillamente porque los habitantes de Ultramar no jugaron en pie de igualdad con los habitantes de la península e islas adyacentes, que contaron con más diputados para representarlos. Ese conflicto originario era latente antes de que comenzara a trabajar la comisión y dio lugar a un funcionamiento que obligaba a recurrir a los reglamentos específicos y concretos para paliar las discriminaciones que previsiblemente iban a sufrir los habitantes de las islas de Ultramar.

Esta primera constitución española dedicó un Título específico para definir cómo sería la sucesión a la corona. El Título IV, Del rey, donde se le dedican cinco capítulos para definir todo lo relativo a su persona y, en concreto, el Capítulo II, De la sucesión a la Corona, son los que nos interesa analizar para dar cumplimiento al título de esta comunicación.

Para corroborar la nula importancia otorgada por las Cortes de Cádiz a las mujeres, es suficiente comprobar que ninguno de los diputados presentes tuvo la más mínima intención de iniciar una polémica sobre la igualdad de géneros a la hora de discutir acerca de la sucesión. Sólo hubo dos diputados que consideraron necesario hacer un debate público sobre el texto presentado por la comisión de Constitución, motivo por el cual se cerró prácticamente sin ninguna modificación y, sobre todo, evitando dar mayores explicaciones al asunto del género que, desde nuestra perspectiva, habría supuesto una mejora indudable del texto.

\footnotetext{
32 Cfr. Diarios..., Tomo IV, sesión del 23 de diciembre de 1810, pág. 217.

Para la de Constitucion, á los

Sres. D. Agustín Argüelles [diputado por el Principado de Asturias].

D. José Pablo Valiente [diputado por Sevilla].

D. Pedro María Ric.

D. Francisco Gutiérrez de la Huerta.

D. Evaristo Pérez de Castro [diputado por Valladolid].

D. Alfonso Cañedo.

D. José Espiga [diputado por Cataluña].

D. Antonio Oliveros [diputado por Extremadura].

D. Diego Torrero [diputado por Extremadura].

D. Francisco Rodríguez de la Bárcena [diputado por Sevilla].

D. Vicente Morales [diputado por Perú].

D. Joaquín Fernández de Leyva [diputado por Chile].

D. Antonio Joaquín Pérez [diputado por América Septentrional].
} 
Una vez admitida la monarquía, gracias a una larga polémica en la que se argumentó desde las más antiguas esencias históricas para justificar su existencia, parece que no había demasiados problemas para admitir un título sobre la sucesión que no debería ser objeto de discusión, una vez explicada tan contundentemente la necesidad de la monarquía hereditaria.

Después de recordar que la Nación entera y las Cortes ya se habían pronunciado y jurado a favor del Señor Don Fernando VII, actual Rey de las Españas, y de su descendencia y sucesores legítimos, se indicó el inicio de un debate sobre los contenidos del capítulo. El señor Aner (Felipe Aner de Esteve, diputado por Cataluña) fue el primero en hablar, iniciando una discusión que para él debía ser pública por tratarse de algo tan importante como la sucesión a la Corona. En contra de esa necesidad se manifestó el señor Caneja (Joaquín Díaz Caneja, diputado peninsular por León), indicando que era innecesario porque había quedado claro en el Congreso que la Monarquía era hereditaria, razón de más para comprender que ese era el fundamento de esa ley, por lo que tuvo una aprobación general, sin ninguna indicación para modificar nada del texto. En contestación, el diputado Aner hizo un ejercicio casi de equilibrismo para pedir un debate, poniendo el ejemplo de los mayorazgos a los que se podía suceder de varias maneras, cuestión similar a la Monarquía hereditaria. Asumido que es hereditaria, debería saberse cómo habría de ser hereditaria. No imagino al señor Aner intentando dar una vuelta de tuerca al texto para indagar en las cuestiones de género y para reordenar la sucesión, pero habría sido un ejercicio interesante para conocer el papel otorgado a las mujeres en este momento. Finalmente, el encargado de poner fin a cualquier hipotética porfía fue el señor Argüelles (Agustín de Argüelles, diputado por Asturias) que insistió en plantear las dificultades que surgirían de hacer público un debate en el que se comprometería la delicadeza del Congreso. Sin duda, Argüelles sabía perfectamente que las cosas se le irían de las manos si se ponían a debatir acerca de la sucesión porque en España había un grandísimo problema a resolver:

«á saber: la revolucion que ha hecho la introduccion de la ley Sálica, y esto es menester que el Congreso lo decida, y no puede hacerlo en el momento sin previa instrucción; el tratarlo en público traería inconvenientes por el derecho que creen tener otras naciones á la sucesion de la Corona».

Con esta intervención Argüelles dejó al resto de los diputados con el temor en el cuerpo y ésa debió ser la razón por la que la sesión terminara sin dar más oportunidades a la polémica. Parecía claro que no tenía ningún interés en discutir en Cortes sobre el Auto Acordado de Felipe $\mathrm{V}$ y sobre la relación del mismo con las normas impuestas en el país vecino por su revolución:

«Llamo sobre esto la atención de V.M.; y si se ha de tratar en público, pido la palabra para exponer mi dictámen ${ }^{33}$.

${ }^{33}$ Diarios.., sesión de 16 de octubre de 1811, p. 2096. 
El final de este capítulo fue la indicación de no haber lugar para deliberar. Así se resolvió este problema y se volvió a poner de manifiesto, como en tantas otras ocasiones, que la mujer apenas existía y que no había ninguna razón para hacerle protagonista de una discusión en Cortes. Sin duda, el comentario sobre la Ley Sálica convirtió el discurso de Argüelles en un dardo arrojadizo, pues se recordaba a los enemigos franceses ${ }^{34}$. Probablemente, aunque no sea ésta la cuestión más valorada en estas líneas, es oportuno darle un espacio porque es una de las materias más importantes acerca de la política internacional que defendería el nuevo estado. El discurso muestra la proximidad de España con Gran Bretaña, más que con Francia, el país invasor. Sin duda, los diputados gaditanos conocían bien la Ley de Partida y les pareció muy adecuado retomar la normativa no escrita, ese sistema cognaticio establecido por la costumbre que había existido en España, antes del Auto Acordado de Felipe $\mathrm{V}^{35}$.

Llegando al Capítulo III, relativo a De la menor edad del Rey y de la Regencia, volvemos a encontrarnos con una situación similar, es decir, con un escenario donde la información aportada para los problemas de las mujeres es la de obviarla, la de pensar que no existe y, en consecuencia, que no forma parte del mundo. Ya en estas fechas lo único reconocido a la mujer era su papel de madre, pues para desempeñar la Regencia se piensa en una Reina Madre, siendo éste uno de los escasos momentos en los que se habla de mujeres en el texto de la Constitución. Parecía como si en el debate de este capítulo en Cádiz solo se hablara de un modelo de reina determinada, es decir de esa reina que se suele encontrar en la historiografía académica tradicional ${ }^{36}$.

En la discusión de este capítulo, encontramos de nuevo una situación donde la mujer queda en entredicho. Después de admitir sin discusión y casi sin debate los dieciocho años como la edad en que el Rey deja de ser menor de edad, y la necesidad de una Regencia para solventar las imposibilidades del monarca, se llega a un punto, en el debate sobre el artículo 190, pues uno de los diputados, el señor Larrazabal tiene dudas sobre si el nombre de Rey comprende también al de Reina, cuestión que para el diputado sería inadmisible. En otras palabras, un heredero varón dejaría de ser menor de edad a los dieciocho años, pero una heredera mujer necesitaría de otras valoraciones para dejar de ser menor de edad con esos años. Los problemas se producían porque la ley $3 .^{a}$, título XV, parte segunda, exigía la edad de veinte años al Rey, pero a la Reina se le exige que sea casada. Esta obligación le parece muy acertada,

34 Vid. VARELa SuAnzes-CARPEgna, Joaquín, «ÁlVARO FLÓREZ ESTRADA UN LIBERAL DE IZQUIERDA», en Moreno LuZÓn, Javier (Ed), PROGRESISTAS, Madrid, Taurus, 2005, p. 23. Desde 1808, Flórez fue un partidario de la lucha contra Napoleón.

35 Vid. ZöPfL, Enrique, Op. Cit.., p. 18.

36 Vid., NASH, Mary (ed.), Presencia y protagonismo. Aspectos de la historia de la mujer, Barcelona, Ediciones del Serbal, 1984. Parece que la historiografía académica tradicional, se ha mantenido en su enfoque habitual, limitándose a tratar a alguna mujer destacada, estadista, santa, reina o reformadora, p. 10. 
«fundándose desde luego en que nuestras leyes se acomodan á la que regularmente sucede estando en mayor grado la prudencia en los hombres; y siendo las mujeres de naturaleza más frágil, por consiguiente, son aquellos de mejor condición en estos casos» ${ }^{37}$.

Sólo con estas frases se podía justificar cualquier desigualdad entre hombre y mujer. Sin embargo, el diputado era más exigente en su petición y se basaba para realizarla en las antiguas leyes de la Recopilación:

«La segunda cuestión es: si antes de cumplidos los 18 años, el Rey ó la Reina contrajeran matrimonio, ¿deben estimarse en la mayoría para que se les entregue el Gobierno del Reino? La razón de dudar, á más de la anterior, consiste en que por la ley $8 .^{a}$, título I, libro $5 .^{\circ}$, de las leyes de Recopilación, se declara que el hijo ó hija, casado ó velado, sea habido por emancipado en todas las cosas para siempre. Así, pido que si lo expuesto merece la atención de V.M., se declare con lo que digan los señores de la comisión» ${ }^{38}$.

La respuesta dada por el resto de los diputados era de considerar el asunto como algo innecesario, pero fue el diputado Argüelles el que dio una solución contundente:

«Por nuestras leyes está prevenido que el que se casa antes de 18 años, entra en el goce de sus bienes, y puede administrarlos; pero no por eso es mayor de edad. En este caso se hallaría el Rey si lo hiciese como lo propone el señor Larrazabal, aunque de cien veces sucederá una»39.

Como indica el diario de sesiones, no se hizo novedad con respecto a dicho artículo. Quedaba muy claro que con esta frase el artículo no sufriría modificaciones y, por tanto, se obviaba cualquier asunto relacionado con la mujer. Según indica M. ${ }^{a}$ Victoria López-Cordón, en las Cortes de Cádiz se había criticado la posibilidad de concederles la mayoría de edad a hombres y mujeres al mismo tiempo, lo cual podía hacer posible que una mujer consiguiera ser mayor de edad antes que un hombre. El asunto se producía porque Carlos IV en 1803 había ordenado que, para contraer matrimonio, era necesario el consentimiento paterno, a los hijos a los 25 años y a las hijas a los 23 años. Si esto ocurría podía considerarse que alguna mujer se casara con esa edad y llegara a ser mayor de edad antes que un varón. Es sorprendente que en las Cortes de Cádiz, buscando alguna justificación para mantener un artículo desigual, se aludiera a una normativa que ya había estado vigente en las Leyes de Toro y en la Novísima Recopilación. En Cádiz se fijó para la mayoría de edad de los herederos una cláusula que ya había servido para el común de la población y que fue criticada precisamente en esas Cortes por permitirle conceder esa posibilidad (la mayoría de edad) antes a las mujeres que a

37 Diarios.., sesión de 19 de octubre de 1811, p. 2115.

38 Diarios.., sesión de 19 de octubre de 1811, p. 2115.

39 Diarios.., sesión de 19 de octubre de 1811, p. 2115. 
los hombres. En cualquier caso, no se obtuvo tampoco ninguna conclusión sobre el particular, permitiendo que quedara sin resolución ${ }^{40}$.

Continuando con las aportaciones del diario de sesiones, llegamos al capítulo IV De la familia Real y del reconocimiento del Príncipe de Asturias, donde manteniendo el típico lenguaje androcéntrico, todo le ocurría a un Príncipe de Asturias varón. El artículo 201 debía indicar cuál sería la denominación del hijo primogénito del Rey y en el debate de dicho artículo, además de las discusiones sobre los ingresos que podría suponer ese título, se escucharon claras muestras de desprecio a la mujer, sobre todo, en la intervención del diputado Cañedo quien consideraba que el título era una pura prerrogativa de honor, pero que era oportuno seguir las pautas de Gran Bretaña, con respecto a su Príncipe de Gales, razón por la que consideraba muy oportuno continuar con las formalidades por las que sólo se era Príncipe de Asturias después de haber sido jurado por las Cortes ahora y, antes por los estamentos. La perla de su discurso, en relación con las mujeres, decía lo siguiente:

«En lo que se ha dicho si se podrá ó no hacer reconocimiento público de una hija del Rey cuando sea sucesora presuntiva por no haber varon, ningun inconveniente hay en ello; es una cosa de hecho que entre otras ocasiones ha sucedido con las infantas de Cataluña y Doña Leonor, juradas sucesivamente Princesas de Asturias, excluida esta por el reconocimiento que se hizo de su hermano D. Enrique IV, por cuyo nacimiento caducó el derecho que ella tenía. Así, me parece que debe continuar el Príncipe heredero con el título de Príncipe de Asturias, como una prerrogativa de honor decorosa para su persona, respetable por su antigüedad, y muy agradable á la Nacion española en cuanto renueva la memoria de sus antiguas relaciones con nuestra generosa aliada la Gran Bretaña ${ }^{41}$.

Leyendo estos discursos, parece como si no hubiera ocurrido nada, como si se estuviera hablando de cualquier otra cosa y no de darle un reconocimiento de algo a una mujer. Esa fue la tónica de ese discurrir. Se llegó hasta el Capítulo V, De la dotación de la familia Real, sin hacer más variaciones sobre la materia que las aquí comentadas, lo cual vuelve a resaltar que sólo pasaron a la comisión de constitución los asuntos que les parecían relevantes a los diputados y no aquellos que tuvieran que ver con hijas de los reyes del sexo femenino.

Consultando el diario de sesiones de las Cortes, parece notorio el deseo de pasar por alto un problema. Argüelles, artífice de la ponencia constitucional, avisó desde el comienzo de lo innecesario que resultaba entrar en ese debate. Para qué se iban a complicar si ya se había dejado muy claro que la corona la heredarían los

40 Vid. María Victoria López Cordón, «La situación de la mujer a finales del Antiguo Régimen (17601860)», en VVAA, Mujer y sociedad en España (1700-1975), MINISTERIO DE CULTURA. Dirección General de Juventud y Promoción Socio-Cultural, p. 83. Según indica la autora, en las Cortes de Cádiz se había criticado la posibilidad de concederles la mayoría de edad a hombres y mujeres al mismo tiempo, lo cual podía hacer posible que una mujer consiguiera ser mayor de edad, si se casaba con autorización paterna, antes que un hombre.

41 Diarios.., sesión de 19 de octubre de 1811, p. 2117. 
sucesores y para qué se iba a discutir sobre el orden de sucesión, si eso sólo podría traer problemas. Parece como si en España hubiera siempre una necesidad de adelantarse a los tiempos, de dejar los escollos sin resolver, esperando situaciones venideras más afortunadas. El problema es que se dejó sin resolver una cuestión que entonces era considerada nimia, «las mujeres no existían», pero los tiempos siguientes marcaron la desigualdad que provocaban tales artículos. Si esa cuestión se hubiera resuelto en su día, pese a todo lo ocurrido en los siglos siguientes, quizás la mentalidad española estaría más acostumbrada a admitir la necesidad de buscar la igualdad.

Finalizado el debate, el texto quedó, en el asunto que nos ocupa, de una forma muy llamativa, pues la lectura del Capítulo II, aprobada por las Cortes proporciona una imagen de igualdad de las mujeres, en cuanto a la sucesión al trono, que no correspondía en nada con el papel otorgado a las mujeres en los debates sustanciales de la constitución.

"Se leyó el capitulo Il de la Constitucion, que trata de la sucesión de la Corona, según lo aprobaron las Cortes en la sesión secreta de 28 de Febrero próximo, y su contenido es el siguiente ${ }^{42}$ :

\section{CAPÍTULO II.}

De la sucesión a la Corona.

Art. 174. El Reino de las Españas es indivisible, y solo se sucederá en el Trono perpétuamente, desde la promulgación de la Constitución, por el orden regular de primogenitura y representación entre los descendientes legítimos varones y hembras de las líneas que se expresarán.

Art. 175. No pueden ser Reyes de las Españas sino los que sean hijos legítimos habidos en constante y legítimo matrimonio.

Art. 176. En el mismo grado y línea los varones prefieren a las hembras, y siempre el mayor al menor; pero las hembras de mejor línea ó de mejor grado, en la misma línea, prefieren a los varones de línea o grado posterior.

Art. 177. El hijo ó hija del primogénito del Rey, en el caso de morir su padre sin haber entrado en la sucesión del Reino, prefiere á los tíos y sucede inmediatamente al abuelo por derecho de representación.

Art. 178. Mientras no se extinga la línea en que está radicada la sucesión, no entra la inmediata.

Art. 179. El Rey de las Españas es el Sr. D. Fernando VII de Borbón que actualmente reina.

Art. 180. A falta del Sr. D. Fernando VII de Borbón sucederán sus descendientes legítimos, así varones como hembras: á falta de, éstos sucederán sus hermanos y tios, hermanos de su padre, así varones como hembras, y los descendientes legítimos de éstos, por el órden que queda prevenido, guardando en todos el de-

${ }^{42}$ Aunque pueda parecer inapropiada una reproducción de todo el articulado del capítulo II, la considero necesaria para resaltar la contundencia de su contenido. 
recho de representación y la preferencia de las líneas anteriores á las posteriores.

Art.181. Las Córtes deberán excluir de la sucesión aquella persona o personas que sean incapaces para gobernar, o hayan hecho cosa por que merezcan perder la Corona.

Art. 182. Si llegasen á extinguirse todas las líneas que aquí se señalan, las Cortes harán nuevos llamamientos como vean que más importa a la Nación, siguiendo siempre el órden y reglas de suceder aquí establecidas.

Art. 183. Cuando la Corona haya de recaer inmediatamente ó haya recaído en hembra, no podrá ésta elegir marido sin consentimiento de las Córtes; y si lo contrario hiciere, se entiende que abdica la Corona.

Art. 184. En el caso de que llegue a reinar una hembra, su marido no tendrá autoridad ninguna respecto del Reino, ni parte alguna en el gobierno ${ }^{43}$.

\section{LA LEY SÁLICA}

Estando segura de la existencia de otras razones para permitir la sucesión al trono de una mujer, veamos cuáles fueron esas razones y por qué se permitió que Fernando VII utilizara todos los resortes constitucionales a su favor, para paliar la ausencia de un heredero varón.

Cuando se instala en España la Casa de Borbón francesa, en la persona de Felipe $\mathrm{V}$, se realiza una innovación importante en la legislación sobre la sucesión al trono. En 1713 Felipe V, con la influencia francesa, dicta una Ley Fundamental por la que se establece la sucesión a la Corona por rigurosa agnación, es decir, con la preferencia siempre del varón sobre la hembra ${ }^{44}$. Los datos más interesantes sobre esta normativa indican que en el caso de fallecer todos los hijos varones de un monarca, tendrán preferencia para la sucesión sus hermanos varones, antes incluso que sus propias hijas. Del mismo modo, si falleciesen todos sus hermanos, tendrían preferencia sus tíos varones, antes que sus propias hermanas, y así sucesivamente en todos los herederos al trono. Esto venía a señalar que las mujeres sólo podrían ser herederas a la Corona, después de haber agotado todas las líneas por varón. Con esta descripción nos encontramos ante la explicación de la conocida como Ley Sálica, una ley importada de Francia y que generó una gran desigualdad en la sucesión a la corona española. Este planteamiento fue el utilizado por el pretendiente carlista, cuando reclamó sus derechos a la sucesión, apareciendo el primer momento de repudio a la mujer en el derecho a la sucesión. Ya señalamos previamente que en el punto de la sucesión, los diputados quisieron reflejar en el texto sus recuerdos normativos, procedentes de las Partidas y de La Recopilación de Leyes. Aún no existía un Código Penal y todas las normas procedían de ese

43 Diarios.., sesión de 17 de marzo de 1812, p. 2937. Los subrayados siempre son de la autora.

44 Rodríguez de Maribona, Manuel M. ${ }^{a}$, Los herederos de la Corona Española. Historia de los Príncipes de Asturias, Madrid, Sotuer, 1996, p. 196. (Desde ahora MARIBONA, Príncipe de Asturias). 
texto ancestral, razón por la cual en el asunto de la sucesión no se piense para nada en alterar esa antigua normativa española, con una ley procedente del país invasor.

Por su parte, el rey Fernando VII, debido a sus dificultades para tener un heredero varón dictó una Pragmática Sanción, por medio de un Real Decreto, en el que ordenaba que a su hija primogénita, Doña Isabel, se le concedieran los honores de Princesa de Asturias, mientras no tuviera un hijo varón. Este texto fue comunicado al Tribunal Supremo el 14 de octubre de 1830, dando lugar a la primera ocasión en la historia de España en la que una mujer era «Princesa de Asturias» por derecho propio y no como consorte.

Desde este momento, en las constituciones españolas del siglo XIX apenas se habla del título de Príncipe de Asturias y se denomina al heredero como «inmediato sucesor» o «heredero inmediato a la Corona», pero manteniendo el espíritu lejano de la rigurosa agnación, es decir, del pariente por consanguinidad respecto de otro, cuando ambos descienden de un tronco común de varón en varón ${ }^{45}$. Los cambios se produjeron avanzado el siglo XIX, cuando se dicta una legislación que introduce una alteración importante. Por Real Decreto de 26 de mayo de 1850, Doña Isabel II estableció que «los sucesores inmediatos a la Corona, con arreglo a la Constitución de la Monarquía, sin distinción de varones ó hembras, continuarán denominándose Príncipes de Asturias, con los honores y prerrogativas que son consiguientes a tan alta dignidad» ${ }^{46}$. Este Real Decreto se hizo efectivo al otorgársele, por segunda vez, a la Infanta Doña Isabel ('La Chata), con motivo de la coronación de su hermano Don Alfonso XII ${ }^{47}$.

En España, la ley Sálica ha conocido diversos recorridos, de los que vamos a mencionar algunos de los más llamativos. Con la muerte de Fernando VII, su hermano, el Infante Don Carlos María Isidro, toma el título de Rey de España, amparándose en la ley que había establecido su bisabuelo, don Felipe V, en la que se separaba a las mujeres del orden sucesorio.

Había cierta confusión en este asunto, pues desde el inicio del constitucionalismo en España, la primera constitución, la de Cádiz, cuando trataba el tema de la sucesión a la Corona, se dispuso que «el hijo primogénito del Rey se titulase Príncipe de Asturias, y los demás hijos, Infantes». En esa constitución se intentaba corregir el carácter agnaticio del régimen sucesorio que había implantado la casa de Borbón, desde la ya mencionada Ley Fundamental del 10 de mayo de 1713. Posteriormente en las constituciones sucesivas de 1837, 1845 y 1876, apenas se menciona esa cuestión.

\footnotetext{
${ }^{45}$ Maribona, Príncipe de Asturias, p. 141.

${ }^{46}$ Gaceta de Madrid, n. ${ }^{\circ}$ 5782, jueves 30 de marzo de 1850. El decreto de 1850 que permitía ser Príncipe de Asturias a varones o hembras, fue anulado por Cánovas del Castillo en 1880.

${ }^{47}$ Maribona, Príncipe de Asturias, p. 142.
} 
Es importante destacar que en 1812 la mayoría de los diputados en Cortes no conocían estrictamente los contenidos de la legislación histórica española, razón por la que desde esa fecha estalló la polémica en el ámbito internacional para debatir acerca de la cuestión sucesoria española que permitiría a la hija de Fernando VII ser Reina, frente a su tío Don Carlos. En la década de 1830 en España se publicaron textos que defendían los derechos dinásticos de la Reina Isabel II, en contra de los de Don Carlos. El trabajo jurídico más importante de los publicados en esas fechas, fue el ya mencionado del doctor Enrique Zöpfl, un jurista alemán, profesor de derecho en la universidad de Heidelberg, que realizó un trabajo en defensa de de la legitimidad de Isabel II en el trono de España, en contra de los defensores de Don Carlos y de los autores de falsas doctrinas. Según este autor los acontecimientos que marcaron la historia legal de la sucesión en España se remontaban a 1037, cuando se estableció, basándose en distintos ejemplos que superan el margen de extensión de este texto, un teorema básico: $10^{\circ} \mathrm{A}$ la corona tenían derecho los varones y las hembras. $2 .^{\circ}$ En la misma línea el hijo primogénito era preferido a los demás, y los varones a las hembras, $3 .^{\circ}$ En líneas diferentes la hembra de línea directa, o de línea más próxima era preferida a los varones de línea colateral, o de línea más remota. $4 .^{\circ}$ En igualdad de línea la preferencia de grado y sexo. Esta era la ley utilizada siempre en España, basada en el uso y la costumbre, aunque no fuera una ley escrita por la que el autor consideraba que se legitimaba plenamente el trono de Isabel II8 .

El Auto Acordado de Felipe V alteraba esta normativa por lo que los diputados gaditanos optaron por retomar el texto ancestral, con el objetivo básico de unirse a Gran Bretaña en el plano internacional y alejarse de Francia que era el país invasor.

En 1812 había otras necesidades para tratar el asunto de la sucesión y, casi seguro, estaban más relacionadas con la política internacional del estado español que con los asuntos de género.

${ }^{48}$ ZöPfL, Enrique, Op. Cit., p.18. 